\author{
MIRJANA PERIĆ 1 \\ SAŠA ILIĆ \\ ANA VUČKOVIĆ \\ ${ }^{1}$ University of Niš, Faculty of \\ Electronic Engineering \\ Imirjana.peric@elfak.ni.ac.rs
}

\section{ANALYSIS OF BOWMAN SQUARES USING HYBRID BOUNDARY ELEMENT METHOD}

Abstract: The characteristic parameters of the Bowman squares are determined using the hybrid boundary element method. Influences of different parameters on characteristic impedance values are analysed. Also, the case of multilayered dielectric is considered. The results for the characteristic impedance have been compared with the results obtained by other methods.

Key words: Bowman squares, characteristic impedance, diamondwise struc-ture, finite element method, hybrid boundary element method.

\section{INTRODUCTION}

Almost 85 years ago, Bowman calculated in [1] the capacitance of the shielded transmission line, with cross-section shown in Figure 1, using the conformal mapping. This "diamondwise" geometry Riblet called "Bowman squares" in [2] and modified the Bowman's procedure in order to avoid the use of complex algebra and some capacitance calculation limitations. The results of mentioned authors, [1] and [2], are compared in [3], where such structure was analysed by Musa and Sadiku using COMSOL, a software based on the finite element method.

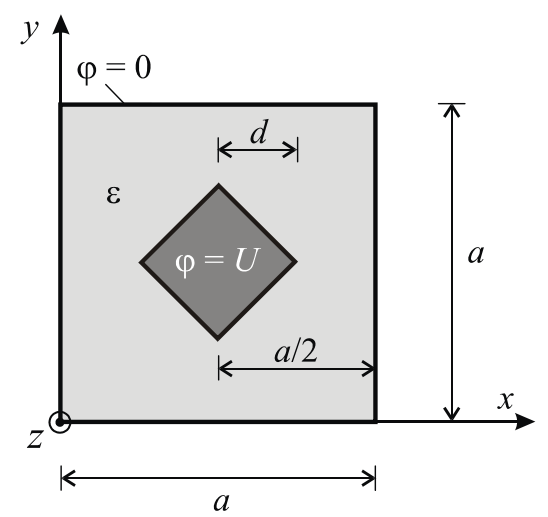

Figure 1. Square within a square (Diamondwise structure)

In order to verify those results and to show the possibility of using a new approach for modelling the considered structure, the hybrid boundary element method (HBEM) is used. Up to now, it has been successfully applied for quasi-static TEM analysis of microwave transmission lines, [4,5]. Also, the geometry from Figure 1 is modelled using FEMM software, [6], based on the finite element method.

The characteristic parameters of this shielded transmission line for different values of permittivity and dimensions will be presented in tables and graphically.

An expansion of Bowman squares structure by adding multilayered dielectric is also considered. An influence of the inner conductor eccentricity is analysed in this paper.

\section{HBEM APPLICATION}

Applying the HBEM procedure, given in [4], an equivalent model for structure from Figure 1 is formed, Figure 2.

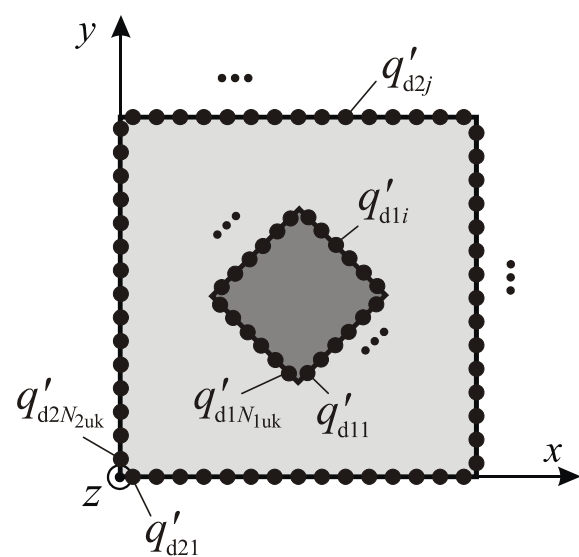

Figure 2. Equivalent HBEM model for structure from Figure 1.

The potential at any point of the system is

$$
\begin{aligned}
\varphi & =\varphi_{0}-\sum_{i=1}^{N_{1 \mathrm{uk}}} \frac{q_{\mathrm{d} 1 i}^{\prime}}{2 \pi \varepsilon} \ln \sqrt{\left(x-x_{\mathrm{d} 1 i}\right)^{2}+\left(y-y_{\mathrm{d} 1 i}\right)^{2}}- \\
& -\sum_{j=1}^{N_{2 \mathrm{uk}}} \frac{q_{\mathrm{d} 2 j}^{\prime}}{2 \pi \varepsilon} \ln \sqrt{\left(x-x_{\mathrm{d} 2 j}\right)^{2}+\left(y-y_{\mathrm{d} 2 j}\right)^{2}},
\end{aligned}
$$

where $q_{\mathrm{d} 1 i}^{\prime}\left(i=1, \ldots, N_{1 \mathrm{uk}}\right)$ and $q_{\mathrm{d} 2 j}^{\prime}\left(j=1, \ldots, N_{2 \mathrm{uk}}\right)$ are unknown line free charges shown in Figure 2. Index " $d$ " denotes line charges placed in dielectric (" $d$ "). With $\left(x_{\mathrm{d} 1 i}, y_{\mathrm{d} 1 i}\right)$ and $\left(x_{\mathrm{d} 2 j}, y_{\mathrm{d} 2 j}\right)$ are given the positions of the equivalent electrodes, and $\varphi_{0}$ is unknown additive constant, that depends on the chosen referent point for the electric scalar potential.

The total number of unknowns $N_{\text {tot }}$, is denoted by:

$N_{\text {tot }}=N_{1 \mathrm{uk}}+N_{2 \mathrm{uk}}+1$ 
Using the point matching method for the potentials of the inner conductor and shield, the system of linear equations is formed. It is necessary to add one more equation in order to calculate additive constant. That equation has been obtained using the electrical neutrality condition:

$\sum_{i=1}^{N_{1 \mathrm{uk}}} q_{\mathrm{d} 1 i}^{\prime}+\sum_{j=1}^{N_{2 \mathrm{uk}}} q_{\mathrm{d} 2 j}^{\prime}=0$.

After solving a formed system, it is possible to determine the capacitance per unit length and characteristic impedance of the geometry from Figure 1.

\section{NUMERICAL RESULTS}

In [3] the Bowman squares with following dimensions and parameters are analysed:

$\varepsilon_{\mathrm{r}}=1, a=4 \mathrm{~mm}$ and $d=1 \mathrm{~mm}$.

The results convergence for such structure is presented in Figure 3. In the same figure, the computation time is denoted with dotted line.

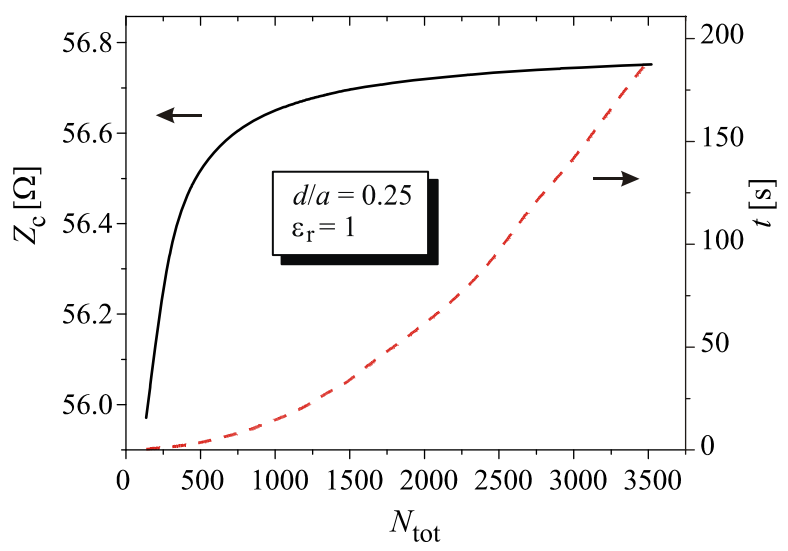

Figure 3. Results convergence and computation time

It is evident that by increasing the number of unknowns the characteristic impedance tends to reach the constant value. The computation time is short and includes the time necessary to:

- determine the equivalent electrodes positions,

- form the system of linear equations,

- solve that system and

- calculate the characteristic parameters.

All following calculations will be done for $N_{\text {tot }}=1800$.

In Table 1, the results from other researchers have been compared with the HBEM and FEMM results. It is evident that obtained results are compliant.
Table 1. Comparison of resukts for characteristic impedance of Bowman squares

\begin{tabular}{ll}
\hline References & $Z_{\mathrm{c}}[\Omega]$ \\
\hline Bowman [1] & 56.745 \\
\hline Riblet [2] & 56.745 \\
\hline Musa \& Sadiku [3] & 58.079 \\
\hline FEMM [6] & 56.711 \\
\hline Zheng et al. [7] & 56.742 \\
\hline HBEM & 56.725 \\
\hline
\end{tabular}

The equipotential lines for structure from Figure 1 are shown in Figure 4.

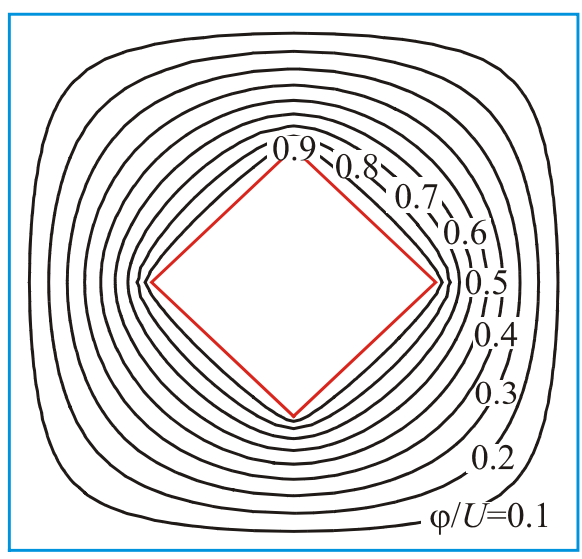

Figure 4. Equipotential lines

The influence of the conductor dimension i.e. the parameter $d / a$, as well as the relative permittivity on the characteristic impedance distribution is given in Figure 5. The obtained results are compared with the FEMM results. Excellent results agreement is obtained.

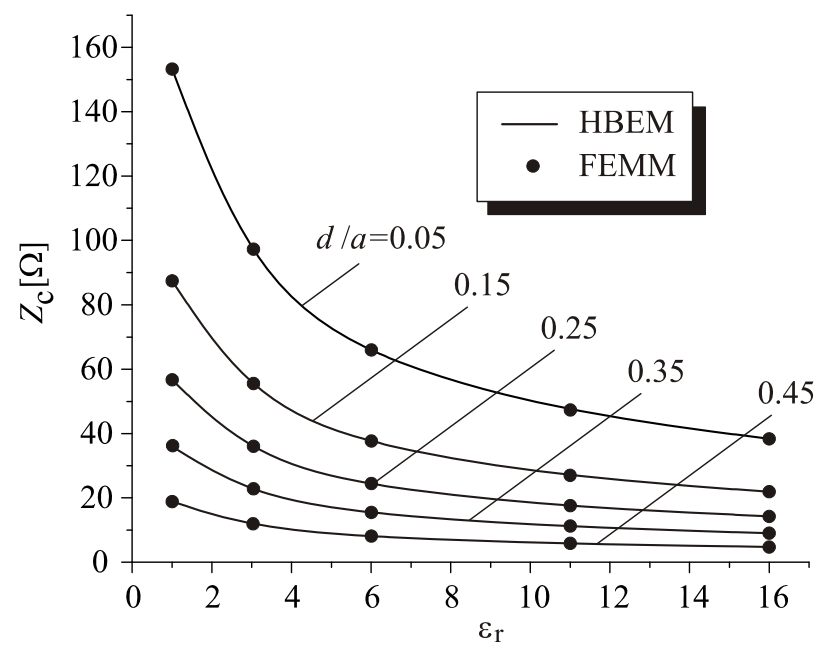

Figure 5. Characteristic impedance distribution versus relative permittivity and parameter $d / a$ 


\section{BOWMAN SQUARES WITH MULTILAYERED DIELECTRIC}

HBEM presents a combination of the equivalent electrodes method (EEM) and boundary element method. The geometry from Figure 1 does not contain multilayered dielectric, so the above described and applied procedure is actually the EEM. In order to show the possibility as well as the main advantage of the HBEM in regard to the EEM, the Bowman square structure is modified. One additional dielectric layer is inserted and the inner conductor is placed eccentrically, Figure 6.

By introducing the total surface charges at the boundary surface between two dielectric layers and using the additional equations obtained from the relation between the normal component of the electric field and the total surface charges [4], the geometry from Figure 6 is solved.

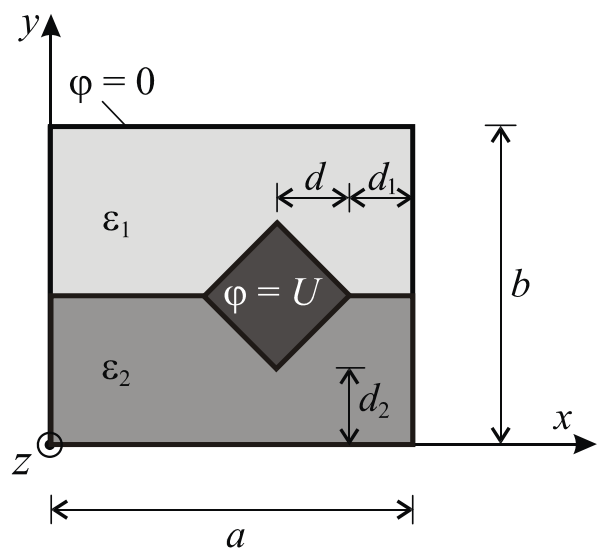

Figure 6. Modified Bowman squares

The equipotential lines for following dimension of modified Bowman squares:

$b / a=0.6, d / a=0.1, d_{1} / a=0.1$ and $d_{2} / a=0.1$, are given in Figure 7 for different values of parameters $\varepsilon_{\mathrm{r} 1}$ and $\varepsilon_{\mathrm{r} 2}$.

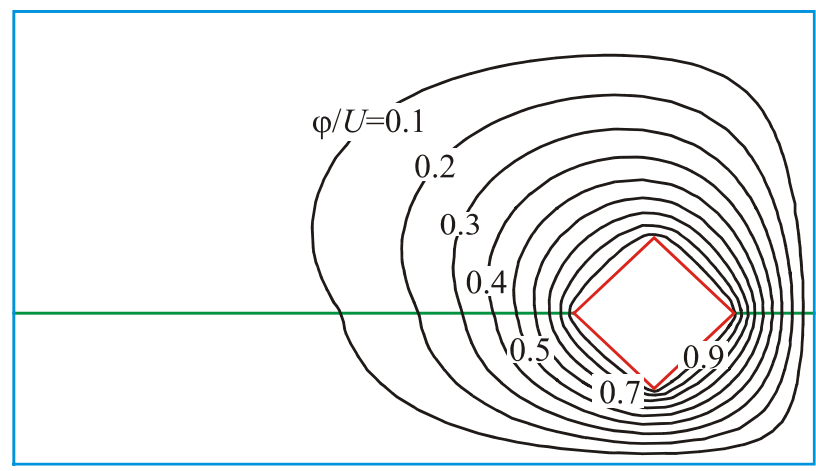

(a)

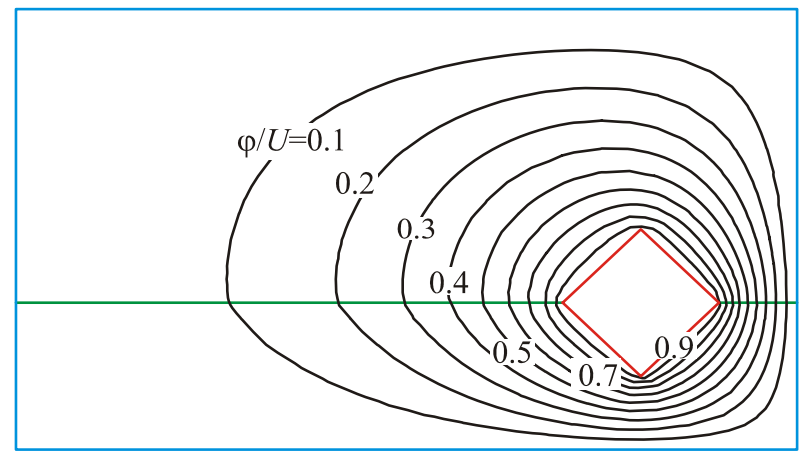

(b)

Figure 7. Equipotential lines for

(a) $\varepsilon_{\mathrm{r} 1}=3, \varepsilon_{\mathrm{r} 2}=16$, (b) $\varepsilon_{\mathrm{r} 1}=16, \varepsilon_{\mathrm{r} 2}=3$.

In Table 2, the characteristic impedance values versus relative permittivities $\varepsilon_{\mathrm{r} 1}$ and $\varepsilon_{\mathrm{r} 2}$ are given. The influences of relative permittivities $\varepsilon_{\mathrm{r} 1}$ and $\varepsilon_{\mathrm{r} 2}$ on effective relative permittivity are shown in Figure 8. The parameters of considered shielded structure are: $b / a=0.6, d / a=0.1, d_{1} / a=0.1$ and $d_{2} / a=0.1$. The results in Table 2 have been compared with FEMM results and they are compliant.

Table 2. Comparison of results for characteristic impedance of Bowman squares

\begin{tabular}{|c|c|c|c|}
\hline \multirow{2}{*}{$\varepsilon_{\mathrm{r} 1}$} & \multirow{2}{*}{$\varepsilon_{\mathrm{r} 2}$} & HBEM & FEMM \\
\hline & & $Z_{\mathrm{c}}[\Omega]$ & $Z_{\mathrm{c}}[\Omega]$ \\
\hline \multirow{5}{*}{1} & 1 & 69.523 & 69.564 \\
\hline & 3 & 47.536 & 47.572 \\
\hline & 6 & 35.455 & 35.483 \\
\hline & 11 & 26.884 & 26.906 \\
\hline & 16 & 22.520 & 22.539 \\
\hline \multirow{5}{*}{3} & 1 & 51.032 & 51.053 \\
\hline & 3 & 40.139 & 40.163 \\
\hline & 6 & 32.036 & 32.058 \\
\hline & 11 & 25.294 & 25.313 \\
\hline & 16 & 21.560 & 21.577 \\
\hline \multirow{5}{*}{6} & 1 & 39.255 & 39.267 \\
\hline & 3 & 33.584 & 33.600 \\
\hline & 6 & 28.383 & 28.399 \\
\hline & 11 & 23.370 & 23.386 \\
\hline & 16 & 20.329 & 20.344 \\
\hline \multirow{5}{*}{11} & 1 & 30.285 & 30.294 \\
\hline & 3 & 27.434 & 27.444 \\
\hline & 6 & 24.364 & 24.376 \\
\hline & 11 & 20.962 & 20.974 \\
\hline & 16 & 18.680 & 18.693 \\
\hline \multirow{5}{*}{16} & 1 & 25.553 & 25.560 \\
\hline & 3 & 23.767 & 23.775 \\
\hline & 6 & 21.682 & 21.692 \\
\hline & 11 & 19.176 & 19.186 \\
\hline & 16 & 17.381 & 17.391 \\
\hline
\end{tabular}




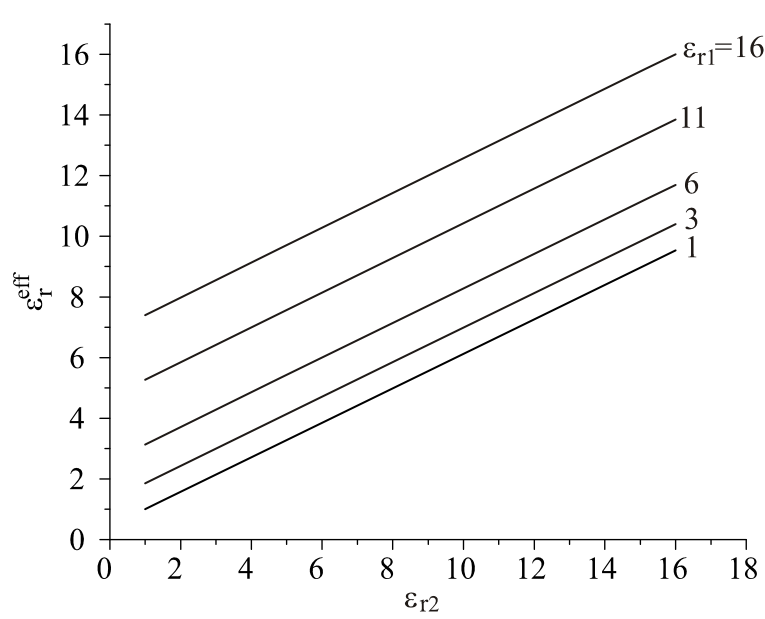

Figure 8. Effective relative permittivity versus relative permittivities $\varepsilon_{\mathrm{r} 1}$ and $\varepsilon_{\mathrm{r} 2}$

An influence of conductor eccentricity on characteristic impedance distribution is shown in Figure 9. By increasing the parameters $d_{1} / a$ and $d_{2} / a$, the characteristic impedance firstly increases than decreases. The parameters of analyzed structure given in Figure 6 are:

$b / a=0.6, d / a=0.1, \varepsilon_{\mathrm{r} 1}=1$ and $\varepsilon_{\mathrm{r} 2}=4.7$.

The characteristic impedance distribution versus inner conductor dimension and parameter $\varepsilon_{\mathrm{r} 2}$ is shown in Figure 10. By increasing the dimension of the inner conductor, as well as the parameter $\varepsilon_{\mathrm{r} 2}$, the characteristic impedance decreases. In this case, the modified Bowman squares dimensions are:

$b / a=1.0, d_{1} / a=d_{2} / a=0.5-d / a$ and $\varepsilon_{\mathrm{r} 1}=1$.

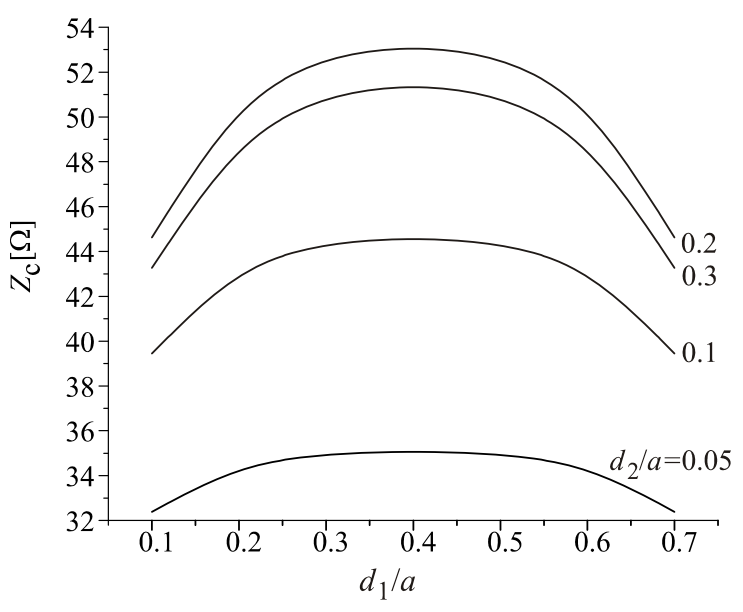

Figure 9. Influence of conductor eccentricity on characteristic impedance distribution

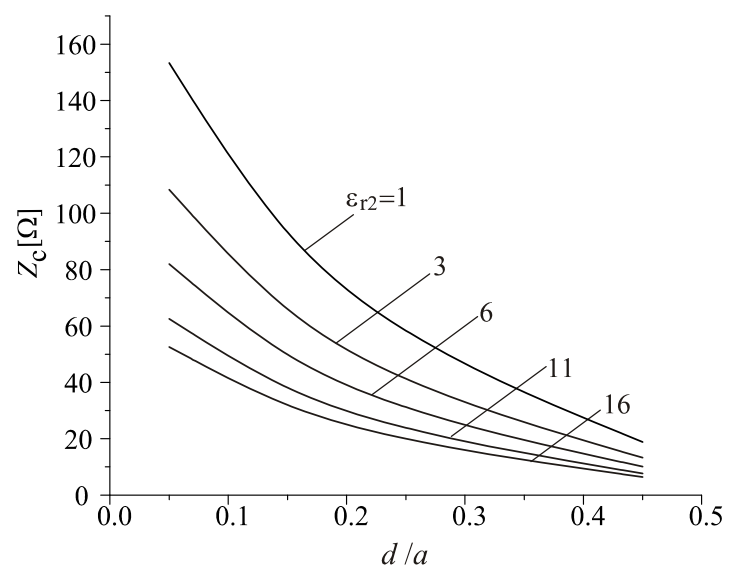

Figure 10. Characteristic impedance distribution versus parameters $d / a$ and $\varepsilon_{\mathrm{r} 2}$

Distribution of the polarized charges per unit length along boundary surface of two dielectric layers is shown in Figure 11 for different values of parameters $\varepsilon_{\mathrm{r} 1}$ and $\varepsilon_{\mathrm{r} 2}$. The dimensions of modified Bowman squares are: $b / a=0.6, d / a=0.1, d_{1} / a=0.1$ and $d_{2} / a=0.1$.

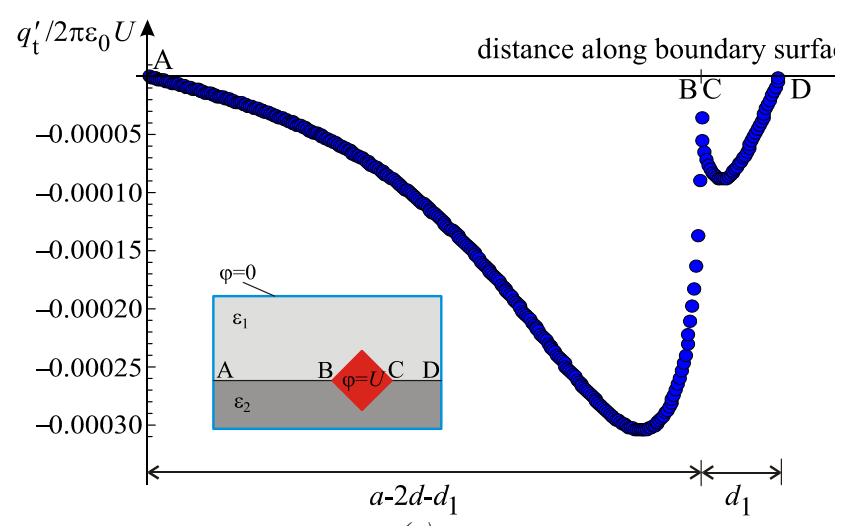

(a)

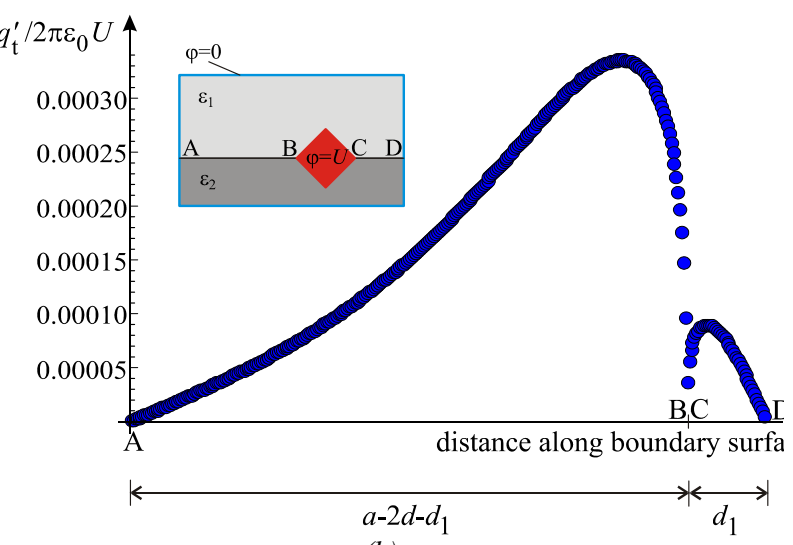

(b)

Figure 11. Normalized polarized charges distribution for (a) $\varepsilon_{\mathrm{r} 1}=3, \varepsilon_{\mathrm{r} 2}=16$, (b) $\varepsilon_{\mathrm{r} 1}=16, \varepsilon_{\mathrm{r} 2}=3$. 


\section{CONCLUSION}

This paper presents a quasi-TEM analysis of Bowman squares and modified Bowman squares using the HBEM. The validity of the HBEM has been successfully checked by comparing the characteristic parameters results with FEMM software and existing results obtained by other researchers. All calculations were performed on a computer with dual core INTEL processor $2.8 \mathrm{GHz}$ and $4 \mathrm{~GB}$ of RAM.

\section{ACKNOWLEDGEMENT}

This research was partially supported by funding from the Serbian Ministry of Education and Science in the frame of the project TR 33008.

\section{REFERENCES}

[1] F. Bowman: "Notes on two-dimensional electric field problems", Proc. London Math. Soc., Vol. 2-41, No. 1, 1936, pp. 271-277.

[2] H. Riblet: "Expansions for the capacitance of the Bowman squares", IEEE Trans. Microwave Theory Tech., Vol. 36, No. 7, 1988, pp. 1216-1219.

[3] S. Musa, M. Sadiku: "Modeling and simulation of shielded microstrip lines", The Technology Interface Journal, No. 8, 2007, pp. 1-22.

[4] S. Ilić, M. Perić, S. Aleksić, N. Raičević: "Hybrid boundary element method and quasi TEM analysis of 2D transmission lines - generalization", Electromagnetics, Vol. 33, No. 4, 2013, pp. 292-310.

[5] M. Peric, S. Ilic, S. Aleksic, N. Raicevic: "Application of Hybrid Boundary Element Method to 2D Microstrip Lines Analysis," International Journal of Applied Electromagnetics and Mechanics, Vol. 42, No. 2, 2013, pp. 179-190.

[6] D. Meeker, FEMM 4.2, http://www.femm.info/wiki/Download

[7] Q. Zheng, W. Lin, F. Xie, and M. Li: "Multipole theory analysis of a rectangular transmission line family," Microwave and Optical Technology Letters, Vol. 18, No. 6, 1998, pp. 382-384.

\section{BIOGRAPHY}

Mirjana Peric was born in Niš, Serbia, in 1976.

She graduated from the Faculty of Electronic Engineering - University of Niš in 2000 and completed her M.Sc. in 2006. In 2015 she received $\mathrm{Ph} . \mathrm{D}$. degree in theoretical electrical engineering from the same faculty. Since 2017, she has been working as an assistant professor at the Department of Theoretical Electrical Engineering at the Faculty of Electronic Engineering in Niš. Her main fields of interest are microstrip transmission lines analysis, numerical and analytical methods for electromagnetic problems solving, EMC. She is an author or co-author of a number of papers published in journals, and presented at national and international conferences.

\section{ANALIZA BOVMANOVIH KVADRATA METODOM HIBRIDNOG GRANIČNOG ELEMENTA}

\section{Mirjana Perić, Saša Ilič, Ana Vučković}

Rezime: Karakteristični parametri Bovmanih kvadrata određeni su korišćenjem metoda hibridnog graničnog elementa. Analizirani su uticaji različitih parametara na vrednosti karakteristične impedanse. Takođe, u radu se razmatra slučaj višeslojnog dielektrika. Rezultati karakteristične impedance se upoređuju sa rezultatima dobijenim drugim metodama.

Ključne reči: Bovmanovi kvadrati, karakteristična impedansa, dijamantna struktura, metoda konačnog elementa, metoda hibridnog graničnog elementa. 